\title{
Mechanisms of Mining Seismicity under Large Scale Exploitation with Multikey Strata
}

\author{
Hu He, ${ }^{1}$ Linming Dou, ${ }^{2}$ Anye Cao, ${ }^{2}$ and Jun Fan ${ }^{2}$ \\ ${ }^{1}$ School of Resource and Earth Science, China University of Mining and Technology, Xuzhou, Jiangsu 221116, China \\ ${ }^{2}$ State Key Laboratory of Coal Resources and Safe Mining, China University of Mining and Technology, Xuzhou, Jiangsu 221116, China \\ Correspondence should be addressed to Hu He; hehu_cumt@126.com
}

Received 23 September 2014; Revised 24 January 2015; Accepted 20 February 2015

Academic Editor: Longjun Dong

Copyright (c) $2015 \mathrm{Hu} \mathrm{He}$ et al. This is an open access article distributed under the Creative Commons Attribution License, which permits unrestricted use, distribution, and reproduction in any medium, provided the original work is properly cited.

\begin{abstract}
The dynamic disasters are aggravating with the increase of exploitation scale and intensity in Chinese coal mines, to further understand this problem, we studied the mechanisms of mining tremors induced by key strata movement and instability under large scale exploitation. First the mechanisms were categorized into two groups that is main key strata fracture and movement as well as subkey strata instability again under adjacent mining activities. Based on the key strata theory in ground control we revealed three basic mechanisms of key strata destabilization that are rotary and sliding of low subkey strata, shear sliding of the high subkey strata, and the main key strata rupture and cave at limit span, respectively. The microseismic observing systems were applied to monitor the mining tremor events and verify the theoretical analysis in different coal mines. The characteristics of time-space evolution of tremors show that low inferior key strata causing the most, followed by the high inferior key strata and the main key strata least, however the released energy was just opposite.
\end{abstract}

\section{Introduction}

Recent years, series of advanced mining technologies such as longwall mining with top coal caving, large height mining, and small or none pillar between adjacent work faces have developed considerably in Chinese collieries [1-4]. With the successful combination of small or none pillar and top coal caving technology, the stress field and spatial structure of overlying strata have become much more complex $[5,6]$. During the process of overlying strata fracture both static and dynamic loads will be applied to the seam, inducing roof and rockburst disaster [7]. Overlying strata movement is not only the result of a single work face, but also the interaction of more faces. Microseismic monitoring results show that the rockburst sources are mainly concentrated in the adjacent gobs especially when thick and hard multikey strata exist, which indicates that spatial structure of overlying strata exists in the coal mine and can evolve dynamically with the exploitation scope changes $[5,8]$.

The roof strata rupture and instability related to mining activities are major concerns in coal science, numerous researches have been done in the past to investigate the roof behavior, and great achievements have been obtained [9-14]. The most important outcomes are the "Voussoir beam" and "key strata" theory of roof strata proposed by Professor Qian, academician of the Chinese Academy of Engineering, which provides the theoretical basis for studying the formation and instability of overlying strata $[15,16]$. Jiang et al. proposed the concept of spatial structure of overlying strata and made four categories, that is, " $\theta$," "O," " $\mathrm{S}$," and "C" types based on the boundary conditions of the work face [17]. The excellent work has important guiding significance for expanding the scope of traditional underground pressure. But we found that most of the previous studies mainly focused on abutment pressure rules confined to a limited zone that is not higher than the main roof; nevertheless, dynamic disasters such as rock bursts, mining tremors, have invoked strata more than the traditional range of main roof, which have been proved by in situ accident investigations. However few corresponding researches on mechanisms of mining tremors under large scale exploitation have been carried out due to lack of efficient precise monitoring means $[18,19]$. Studies on the mechanisms 


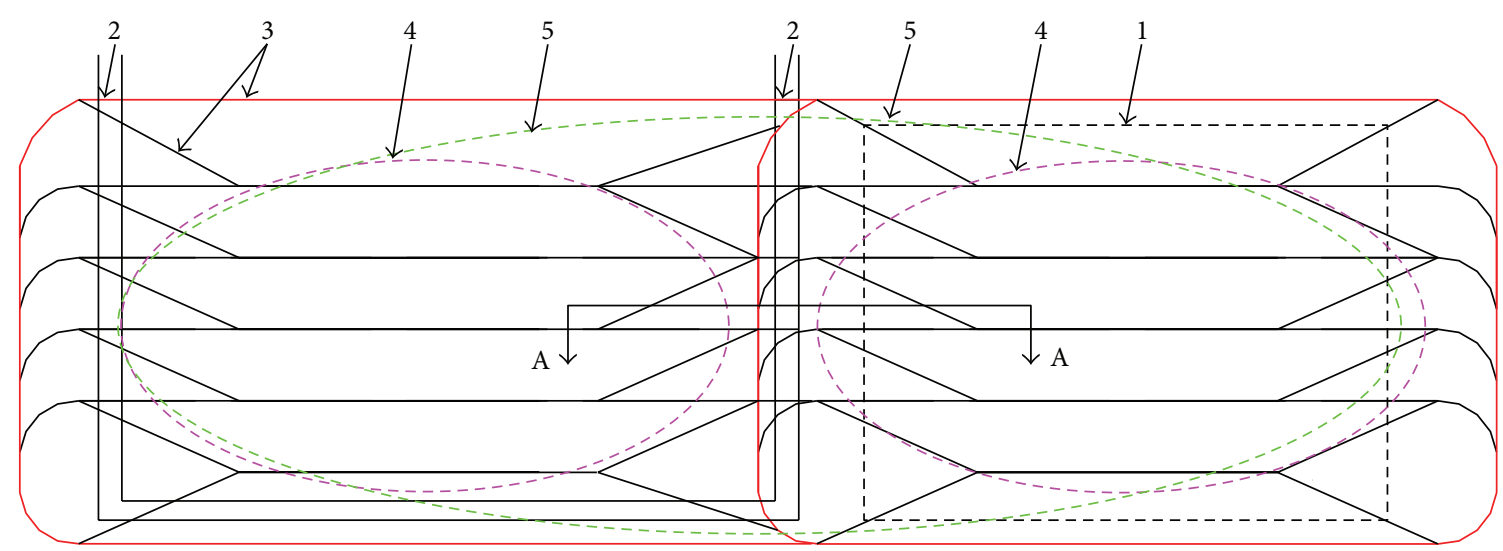

(a) Planar graph

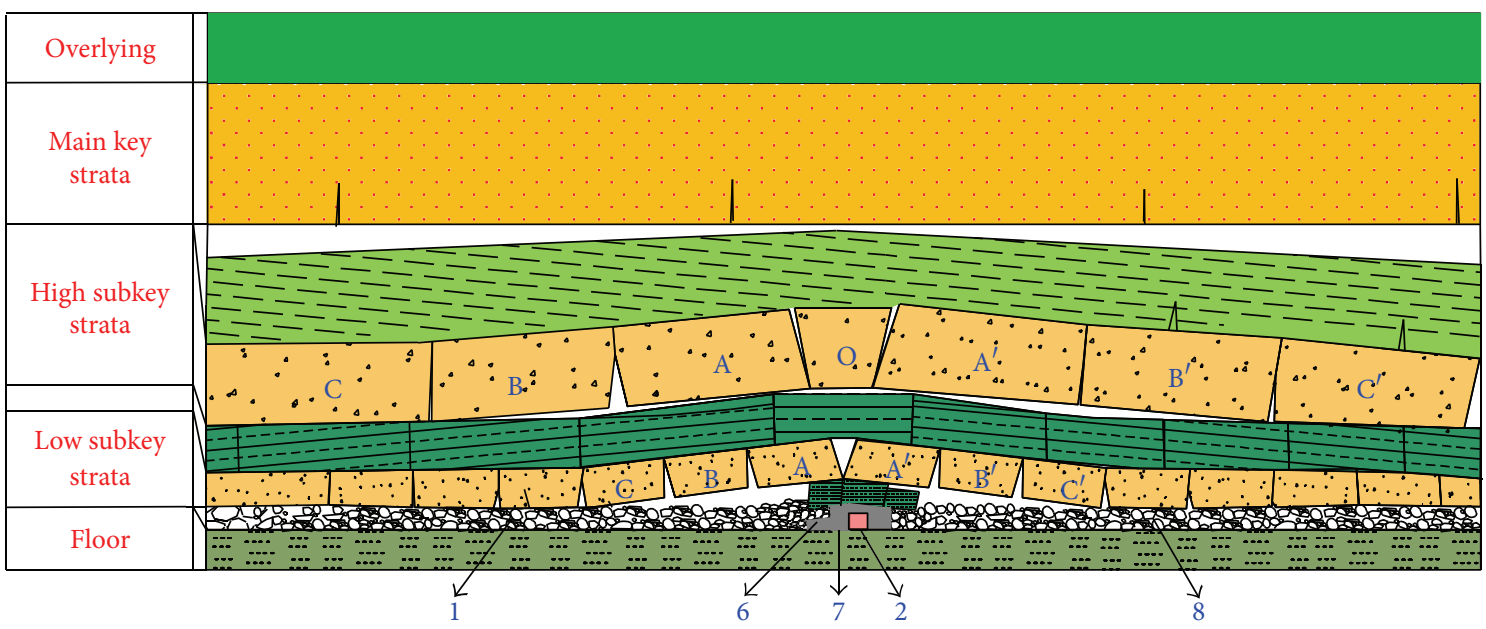

(b) A-A profile graph

FIGURE 1: Schematic structure chart of overburden strata after two work faces exploitation: (1) adjacent gob, (2) district sublevel entry of the longwall face, (3) fracture line of the low subkey strata, (4) fracture line of the high subkey strata, (5) fracture line of the main key strata, (6) face end of the adjacent gob with uncaving top coal, and (7) small pillar between two faces 8-longwall face; (A, B, and C) block of the fractured key strata.

and laws of mining tremors caused by key strata fracture and movement are of great meanings for effective prevention and disaster control.

\section{Classification of the Multikey Overlying Strata}

Thick hard strata that play key roles in the movement of overlying strata are defined as key strata which can be divided into two types: main key strata whose broken and caving will lead to synergistic effect until the surface and inferior key strata that only control local area [17]; normally more than one inferior key stratum and just one main key stratum lay in the overlying beds according to the definitions. The structure known as "Voussoir beam" formed by the fractured key strata still exists and bears the weight of overlying load.

The traditional classification of the overlying strata is based on the controlling rules for the subsidence. The key strata have similar function in ground control rather than instability mechanism and fracture type especially under larger scale exploitation. So we need to make some new definitions in order to predigest the researches based on the instability mechanism. Figure 1 illustrates the structure formed by the key strata when more work faces are exploited, the key strata are classified into three categories according to relationship of the fracture line between two work faces: (1) low subkey strata sharing the same fracture line, (2) high subkey strata with separate fracture line, and (3) main key strata that span limit exceeding the width of one work face at least (Figure 1(b)). Because of different boundary conditions, there are three different instability mechanisms that is rotaryslipping of low subkey strata, shear-sliding instability of high subkey strata and tensile failure, and then shear-sliding of the main key strata. The damage intensity and modes of mining tremors induced by key strata instability will be distinctive significantly because of different destabilization mechanism. 


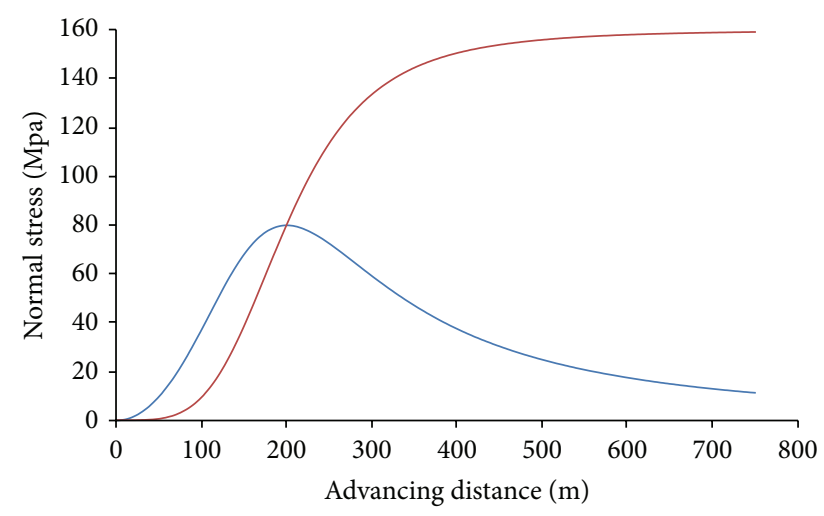

FIGURE 2: Curve of relationship between normal stress and the plate length.

\section{Instability Mechanism of the Key Strata}

3.1. Instability Mechanism of Main Key Strata and the "Square Effect". The main key strata is characterized by great thickness, high strength, and large caving interval, and in some coal mines the main key stratum keep integrated and stable until there are two or more working faces without big pillars between each other. It is known that most overlying strata of coal seams are sedimentary with obvious layers and weak planes which can be separated easily under shearing stress, so the main key stratum can be regarded as thin plate to analyze the stress distribution under the fixed boundary conditions using Navier's solution [20], and we can obtain the normal stress on the strike and dip direction, respectively:

$$
\begin{aligned}
\sigma_{x \max } & =\frac{12 \mu q a^{4} b^{2}}{\pi^{2} h^{2}\left(3 a^{4}+2 a^{2} b^{2}+3 b^{4}\right)}, \\
\sigma_{y \max } & =\frac{12 \mu q a^{2} b^{4}}{\pi^{2} h^{2}\left(3 a^{4}+2 a^{2} b^{2}+3 b^{4}\right)},
\end{aligned}
$$

where $a$ is the distance of the work face advancement, $b$ is the width of the work face, $\mu$ and $h$ are the Poisson's ratio and thickness of the main key strata, respectively, and $q$ is load on the main key strata.

Assume that $\mu=0.25, h=5 \mathrm{~m}$, and $b=200 \mathrm{~m}$; we can obtain the changes of $\sigma_{x \max }$ and $\sigma_{y \text { max }}$ with the advancing distance, as shown in Figure 2, only the short side of the plate is variable that influences the $\sigma_{x}$ and $\sigma_{y}$ with the advancing of the work face, and $\sigma_{x}$ is greater than before $a=b$ and rapidly reaches its maximum when $a=b$, so the roof strata are easily fractured when the plate is square; this phenomenon is called "square effect" which is very common in some coal mines in southeast China. If the main key strata are stiff enough and keep integrated, $\sigma_{x}$ would attenuate while $\sigma_{y}$ starts rising rapidly and plays the leading role in controlling the rupture and stability of the main key stratum plate until $a=2 b$, at that moment it is the second "square effect."

In the process of the main key strata fracturing and sliding between breakage rock blocks, most of the accumulated elastic strain energy released to damage the rock body and a small part about $1-10 \%$ transforms into seismic wave inducing the mining tremors as shown in Figure 3.

3.2. Instability Mechanism of Low Subkey Strata. The stability of the rock blocks in next goaf especially on the boundary significantly affected the strata behaviors of the working face, and mining tremors occurred frequently around the roadways and in the gob. Figure 1 illustrates "Voussoir beam" structure diagram of rupture roof formed after coal excavation. A triangle roof plate with arc side above the faceends with one side fractured in the coal seam 2-10 $\mathrm{m}$ away from the wall and another side hinged with blocks B and C can form the three-hinged arch equilibrium structure. This structure is supported by the coal pillar, top coal at the faceend, immediate roof and rock block $\mathrm{B}$, and can maintain a relative balanced state until the beginning of the coal exploitation in the next longwall face. With the next working face advanced, the solid coal, and immediate roof which supported the "triangle roof plate with arc side" continuously caved and extracted, the location of fractured line would inevitably coincide with the subkey strata of the previous face, so they belong to the low subkey strata. The two key rock blocks $\mathrm{A}$ and $\mathrm{A}^{\prime}$ above the face end are hinged together like a "tower" whose stability was affected by the rotary and sink of block A'. To analyze mechanical balance of the low subkey strata structure, a model (Figure 4) was established taking the rock blocks which play a leading role for studying objects.

The minimal horizontal force $T_{2}$ which maintains the structure balance can be solved by the moment equilibrium on point $\mathrm{O}, \sum M_{0}=0$, so one has

$$
\begin{aligned}
M+ & G l \cos \alpha+Q_{2} l_{2}+T_{1} \frac{1}{2} a \\
= & Q_{1} l_{1}+T_{2}\left[2 l\left(1-\sin \alpha-\frac{1}{2} a\right)\right]+R_{2} 2 l \cos \alpha \\
& +f_{2}\left(h-\frac{1}{2} a\right) .
\end{aligned}
$$
obtains

Using the force equilibrium in $Y$ direction $\sum F_{Y}=0$, one

$$
T_{2}=T_{1}+\left(f_{1}+f_{2}\right) \cos \alpha
$$

Substituting (3) into (4) leads to the critical horizontal force:

$$
T_{2}=\frac{M+G l \cos \alpha+Q_{2} l_{2}+(a / 2)\left(f_{1}+f_{2}\right) \cos \alpha-Q_{1} l_{1}-R_{2} 2 l \cos \alpha-f_{2}(h-a / 2)}{[2 l(1-\sin \alpha)-a]}
$$




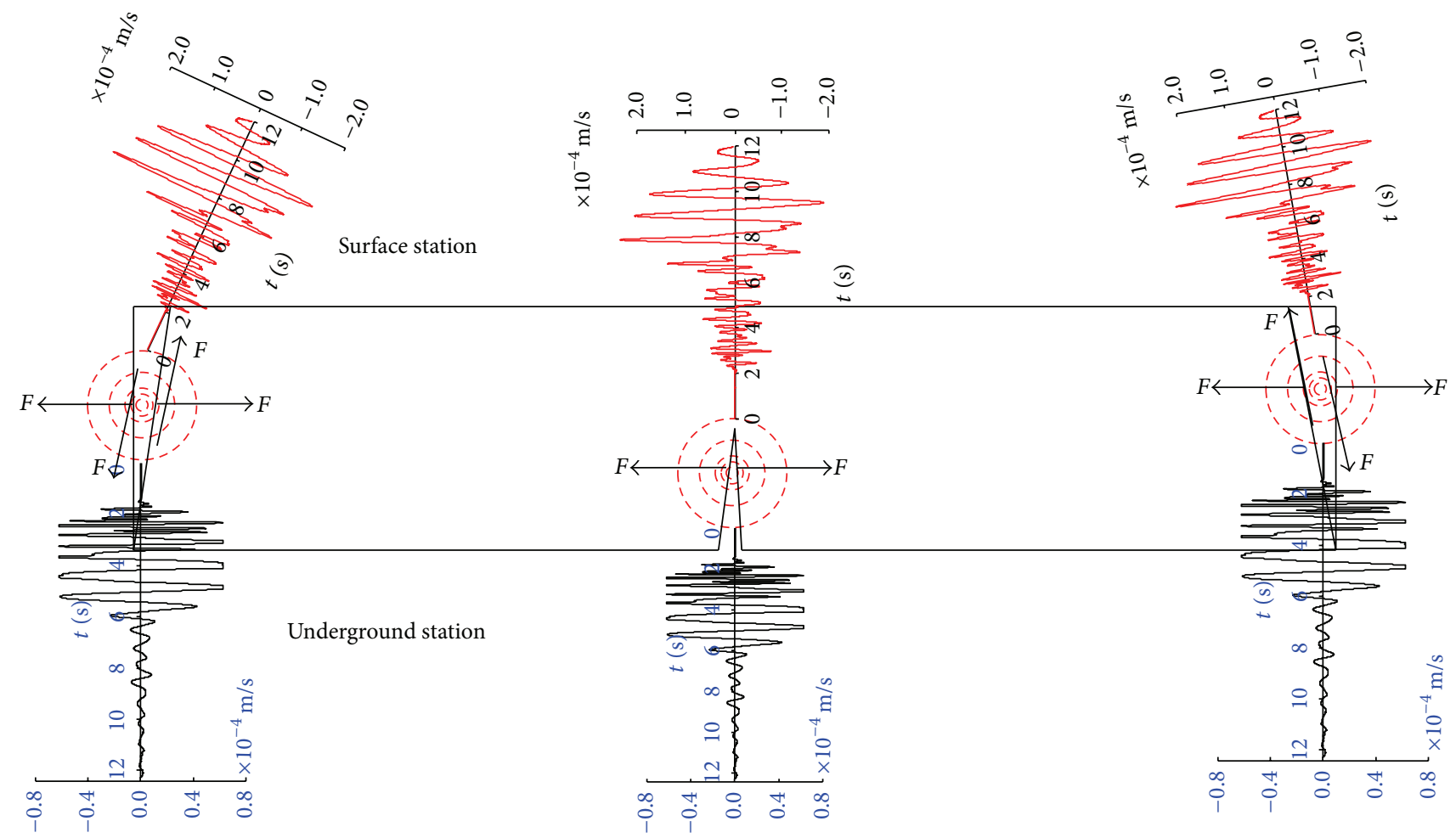

FIGURE 3: Mining tremors induced by main key strata rupture and waveforms recorded by microseismic system.

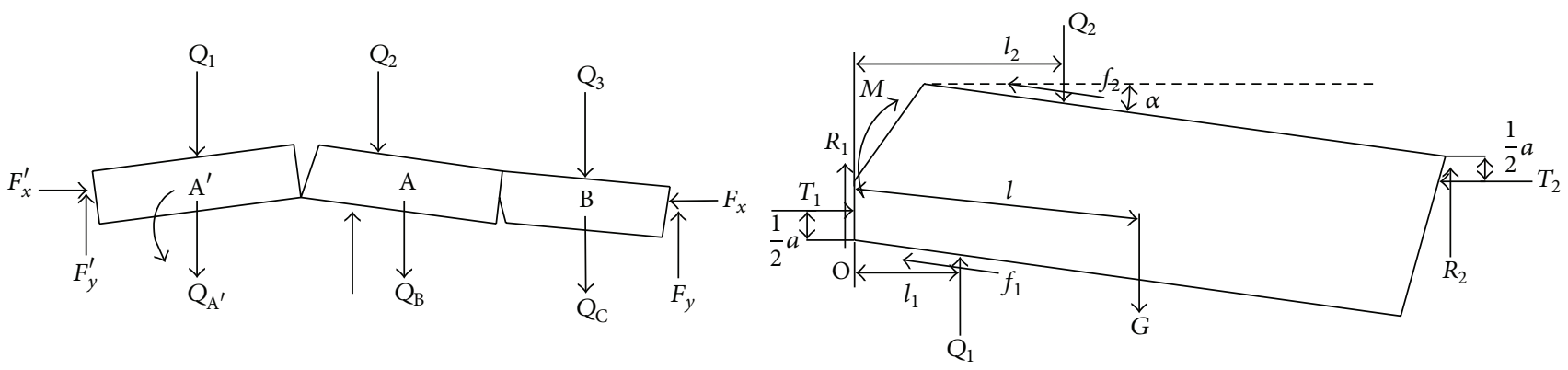

FIGURE 4: Mechanical model of the low subkey rock block.

where $M$ is the moment during the key rock block $\mathrm{A}^{\prime}$ rotary and subsidence to block $A, G$ is the weight of block $A, Q_{1}$ is the caved top coal and immediate roof at the face end, $Q_{2}$ is the load from overlying strata, $f_{1}, f_{2}$ are friction between block $A$ and upper and lower layers, respectively, $T_{1}$, $R_{1}$ are constraint forces from block $\mathrm{A}^{\prime}, T_{2}, R_{2}$ are constraint forces from block $\mathrm{B}^{\prime}, l_{1}, l_{2}$ are the distances from the load $Q_{1}$, $Q_{2}$ to point $O$, respectively, $l, h$ are the length and height of block B, $a$ is the length of the plastic zone on the hinge point of the block A and $a=(l-h \sin \alpha) / 2$, and $\alpha, \varphi$ are rotation and friction angles, respectively.

The condition that no sliding instability occurred between blocks A and B can be expressed as the following equation:

$$
T_{2} \cdot \tan \varphi \geq R_{2}
$$

Equation (5) shows that being affected by the rotary movement of rock block A', the "Voussoir beam" structure composed by blocks $\mathrm{A}^{\prime}, \mathrm{A}$, and $\mathrm{B}$ needs much more huge horizontal force to keep the balance. Figure 5 shows that the critical horizontal force nonlinearly increases with the growth of the rotary angle while the horizontal force $T_{2}$ actually decreases gradually since the hinge area between $\mathrm{A}^{\prime}$ and $\mathrm{A}$ reduces and finally separates at the worst situation so the structure is in an unstable equilibrium that is hard to preserve. So the low subkey strata have two kinds of focal mechanism, rotary instability as the rotation angle exceeds the limitation between blocks $A$ and $A^{\prime}$ and slipping instability between blocks $\mathrm{A}$ and $\mathrm{B}$. In the process of rotary and slip a part of energy released seismic wave which is the mechanism of seismicity in the gob, but with low seismic energy since the low subkey strata have already fractured to different degree which can also be proved by the insite monitoring. 


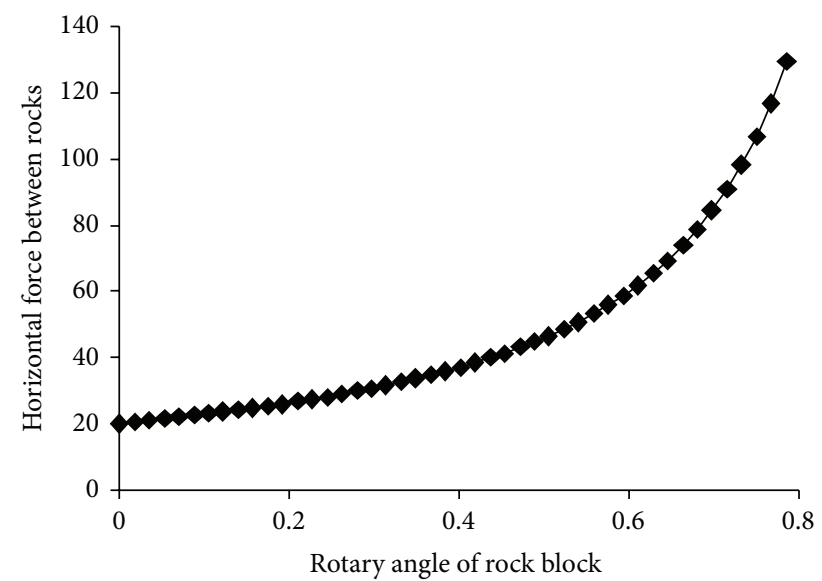

FIGURE 5: Curve of relationship between horizontal force and rotary angle.

3.3. Instability Mechanism of High Subkey Strata. The fracture lines of high subkey strata above the two neighboring longwall faces do not coincide with each other so the structure is more stable than the low subkeys strata as the rock mass in the middle of the fracture lines can resist and buffer the mine disturbance to a considerable extent; therefore, together with the rocks on both sides a balanced structure like a "bridge" is formed. Mining tremors occurring in this area have much more energy than low subkey strata because of huger accumulated energy in the structure system as inadequate fracture and larger rock blocks. We can analyze the mechanical equilibrium criterion based on Figure 1 , horizontal forces $T_{1}$ and $T_{2}$ were applied to the intermediate rock block by side blocks $\mathrm{A}$ and $\mathrm{A}^{\prime}$, respectively. The high subkey strata above the working face rupture rotate and sink with the process of roof caving, the horizontal force $T_{1}$ applied to block $\mathrm{O}$ grows with the increase of rotation angle at first and gradually exceeds the strength criterion, and a shear failure finally forms along the bottom surface which would transform the fixed hinge to roller bearing and reduce the maximum horizontal reaction force supplied to blocks $A$ and $\mathrm{A}^{\prime}$; thereby block $\mathrm{A}$ can move to the central block O leading to slip instability between A and B and induce mining tremors finally. By analyzing the movement and instability process of the high subkey strata, we can know the reasons of mining tremors occurred in this area first because of the shear failure of rock block $\mathrm{O}$ and then sliding between rock block $\mathrm{A}$ and $\mathrm{B}$, finally instability of the lowers strata induced by the sinking of the high subkey strata. Therefore, the released energy of tremors caused by high subkey strata is much higher, which can also be proved by in-site investigations.

\section{Seismic Monitoring of Mining Tremors Induced by Key Strata Movement}

\subsection{Case 1: Mining Seismicity Induced by Subkey Strata}

4.1.1. Introduction of Microseismic Monitoring System. The mining tremors occur frequently and induced tens of rock

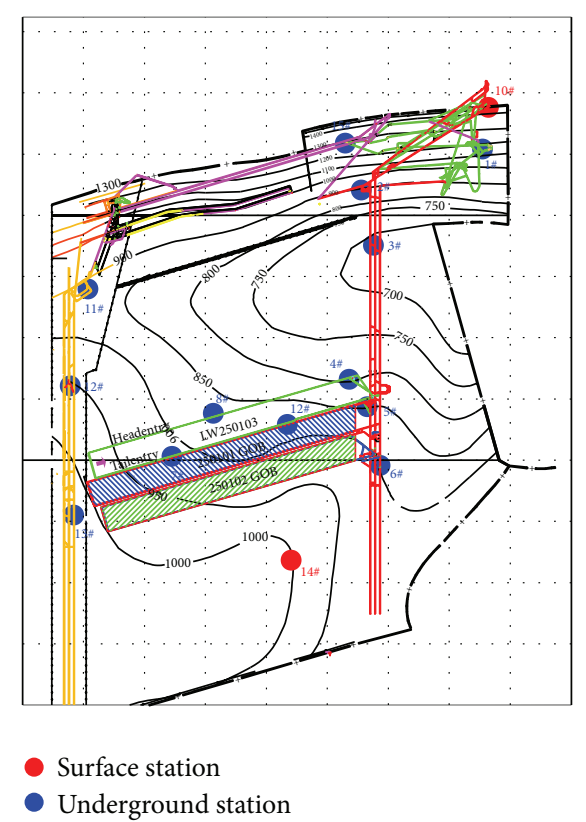

FIGURE 6: Layout of the mining seismic monitoring system installed in Huating coal mine.

bursts that caused great damage to the work face and roadways; hence, the Seismological Observation System called "SOS" for short was introduced to monitor the seismic evens. The "SOS" developed by the Central Mining Institute of Poland is one of the most advanced monitoring equipment in the world. It comprised the seismic data transmission system with maximum distance of $10 \mathrm{~km}$, seismic geophones of frequency band 1-600 Hz, and the AS-1 Seismic Recording System. It can accurately determine the source parameters such as occurring time, coordinates, and energy of the low energy tremors of the order $10-100 \mathrm{~J}$ with the horizontal location error less than $20 \mathrm{~m}$, the vertical error $50 \mathrm{~m}$ under the optimal configuration of seismological network.

4.1.2. Introduction of the Coal Mine. The Huating coal mine in Northwest China is now extracting the third fully mechanized top coal caving longwall face LW250103 in the first district of second lever. LW250103 is adjacent to the 250102 gob in the west with a $5 \mathrm{~m}$ width pillar between each other and solid coal seam in the east with $200 \mathrm{~m}$ face length. The coal seam is $12 \mathrm{~m}$ thick with an average dip angle of 5 degrees, the immediate roof is mudstone of about $7.5 \mathrm{~m}$ thick and $30 \mathrm{~m}$ fine sandstone constitutes the main roof and also plays the role of subkey strata, and $20 \mathrm{~m}$ gritstone with gravel $80 \mathrm{~m}$ away from the coal seam is analyzed to be main key strata. Figure 6 shows the layout the SOS network of Huating mine.

4.1.3. Character of the Mining Seismicity Induced by the Subkey Strata. During the exploitation of LW250102 which was adjacent to LW250101 and a $20 \mathrm{~m}$ width coal pillar between them, mining induced tremors occurred frequently. The locations of the tremors mainly concentrated within LW250102 and most of the big tremors located in the coal pillar but very 


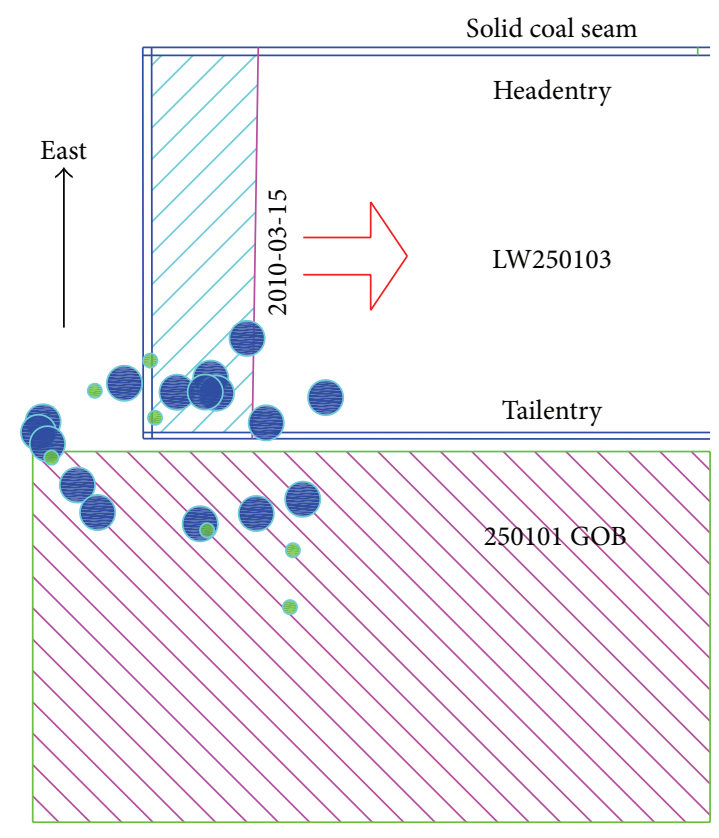

(a) March 1-15 with energy between $10^{3}$ and $10^{5} \mathrm{~J}$

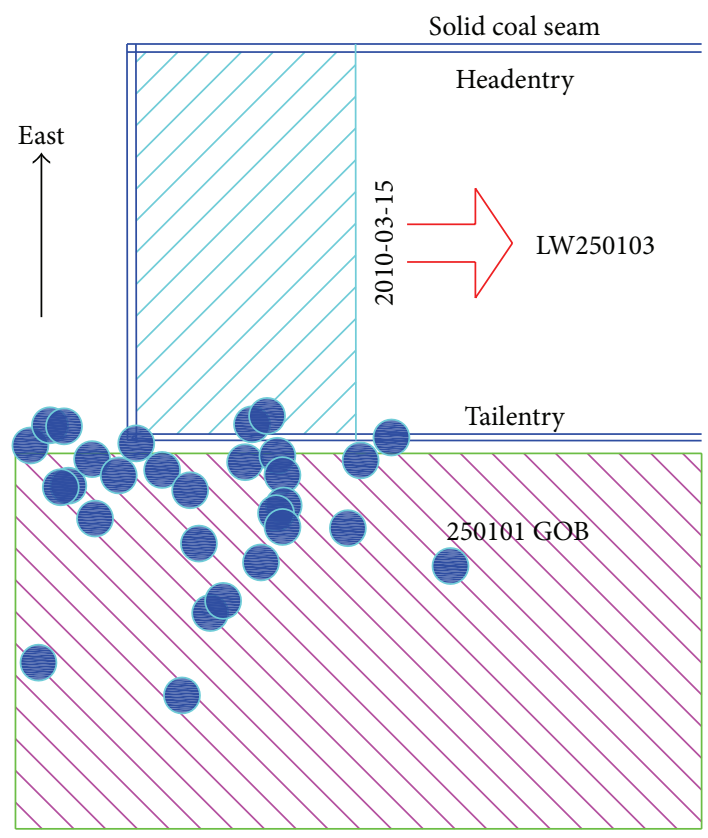

(c) March 15 to April 1 with energy between $10^{3}$ and $10^{5} \mathrm{~J}$

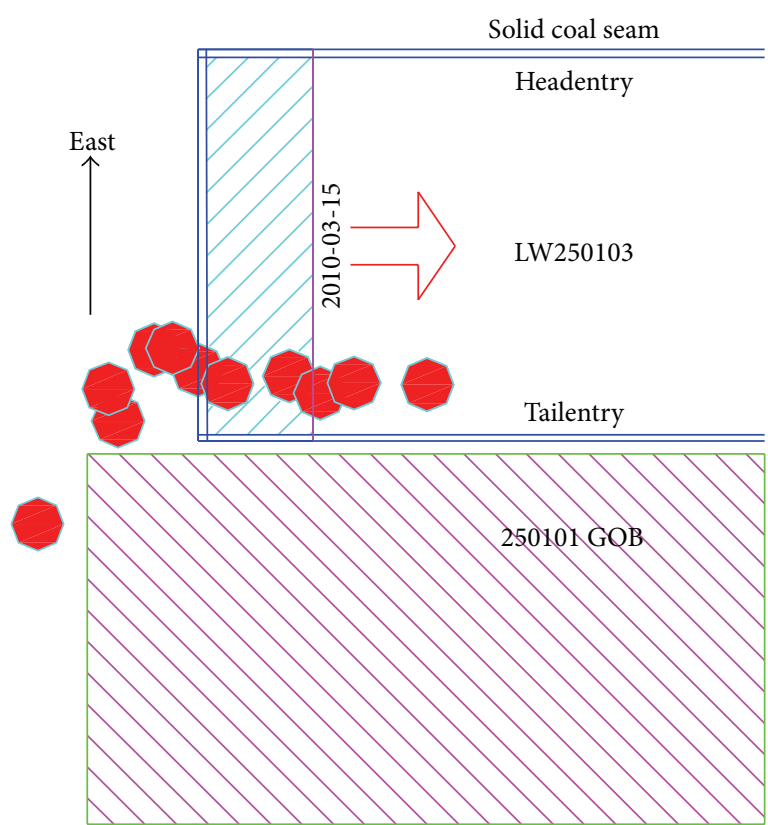

(b) March 1-15 with energy exceeding $10^{5} \mathrm{~J}$

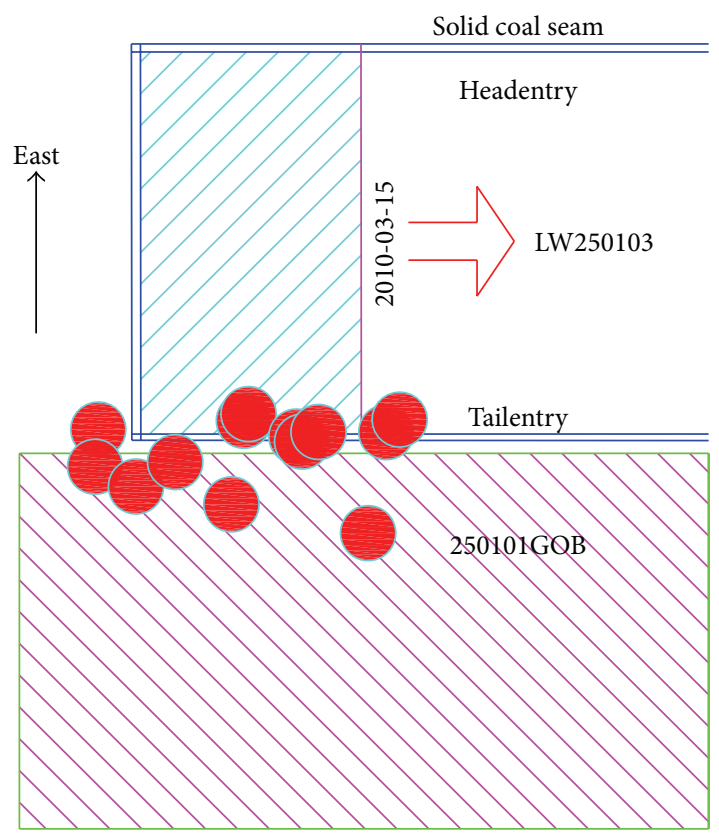

(d) March 15 to April 1 with energy exceeding $10^{5} \mathrm{~J}$

Figure 7: Distribution of seismic source close to the gob side of LW250103.

few in 250101 gob, which indicated the $20 \mathrm{~m}$ wide coal pillar can effectively separate the connection of overlying strata movement between LW250102 and 250101 gob. In order to solve the pillar-burst problem, small pillar that is $5 \mathrm{~m}$ wide was adopted between LW250103 and 250101 gobs, but when LW250103 is mining, lots of tremors were located in 250101 gob and induced several rockburst accidents to the gob-side roadway, causing difficulties for normal production.

The time-space evolution process can reflect the rupture and movement of the overlying strata, for example, in the period that is from the beginning of the mining to the first weighting of the main roof, especially when the work face advanced ahead $120 \mathrm{~m}-150 \mathrm{~m}$ from the open-off cut, the frequency and total energy per day increased sharply and extended to 250101 gob, as Figure 7 shows. Figure 7(a) reveals that at the beginning of coal mining from March 1 to 15 small tremors with energy lever of $10^{3}$ to $10^{5} \mathrm{~J}$ distribute averagely on the tailentry side and in the gob, all close to the small pillar. Tremors in LW250103 are about $20 \mathrm{~m}$ away from the tailentry that suggests the location of fracture line; 
meanwhile tremors in the gob are $30 \mathrm{~m}$ from the coal pillar which determines the length of fractured rock block whose instability is responsible for the seismicity. Figure 7(b) shows the location of big tremors in the same period with energy exceeding $10^{5} \mathrm{~J}$ that mainly is concentrated in the work face forming a rupture zone almost parallel to the tailentry of a $20 \mathrm{~m}$ distance, and elevation of these tremors is $1020 \mathrm{~m}$ averagely that is about $30-40 \mathrm{~m}$ above the coal seam. But few big tremors occur 250101 gob from which we can determine the instability process of the subkey strata in the gob lags behind that in the work face area. Figures 7(c) and 7(d) demonstrate the seismicity distribution in the region 120 to $150 \mathrm{~m}$ away from the open-off cut where the first weighting of main roof happened, and tremors scatter intensively and have a tendency of spreading to the central gob. Mechanism of these big tremors is due to the instability of F-structure of key strata. The upward tendency regulation of the seismic source location can be revealed since the elevation of these tremors during March 15 to April 1 is 1080 m, 60 m higher than those during March 1 to 15.

\subsection{Case 2: Mining Seismicity Induced by Main Key Strata}

4.2.1. Introduction of the Coal Mine. The fully mechanized top coal caving LW10302 in number 10 district of Baodian colliery in southeast China is the second work face from the south boundary and is surrounded by gobs also called "isolated island" encountering mining earthquakes severely, so the 20-channel "SOS" was installed in the coal mine and nine stations were arranged around number 10 district in which there are seven in underground and two on the surface in order to monitor the tremors; the locations are given in Figure 8.

The coal seam is $8.7 \mathrm{~m}$ thick with a huge thick fine sandstone stratum arranged from $100 \mathrm{~m}$ to $150 \mathrm{~m}$ overlying about $200 \mathrm{~m}$ away from the coal seam. As can be calculated based on the key strata theory the huge thick stratum is the main key stratum with the limit span exceeding $350 \mathrm{~m}$, which indicates after the winning of LW10301 the main key strata can still keep integrated and bears the overburden. So the south zone of LW10302 is subcritical extraction while the north area is full subsidence because of large scale of gobs. According to the theory analysis of the normal stress distribution rules with the work face length and width, we can conclude the stress will increases 64 times when the width doubles, so in most cases will exceed the limit of the main key stratum. Thus, during the extraction of LW10302 the main key strata are most likely to rupture.

4.2.2. Mechanism of Mining Tremors Induced by Key Strata Movement under Large Scale. A total of 40 big mining earthquakes with energy exceeding $10^{5} \mathrm{~J}$ occurred during the LW10302 extraction from July 15, 2008, to April 30, 2009. These big tremors caused surface buildings quake, underground space damage but no real coal bump in the work face and roadways (Figure 9). The locations of these big mining earthquakes revealed by the "SOS" monitoring results are situated in the main key strata also called "red

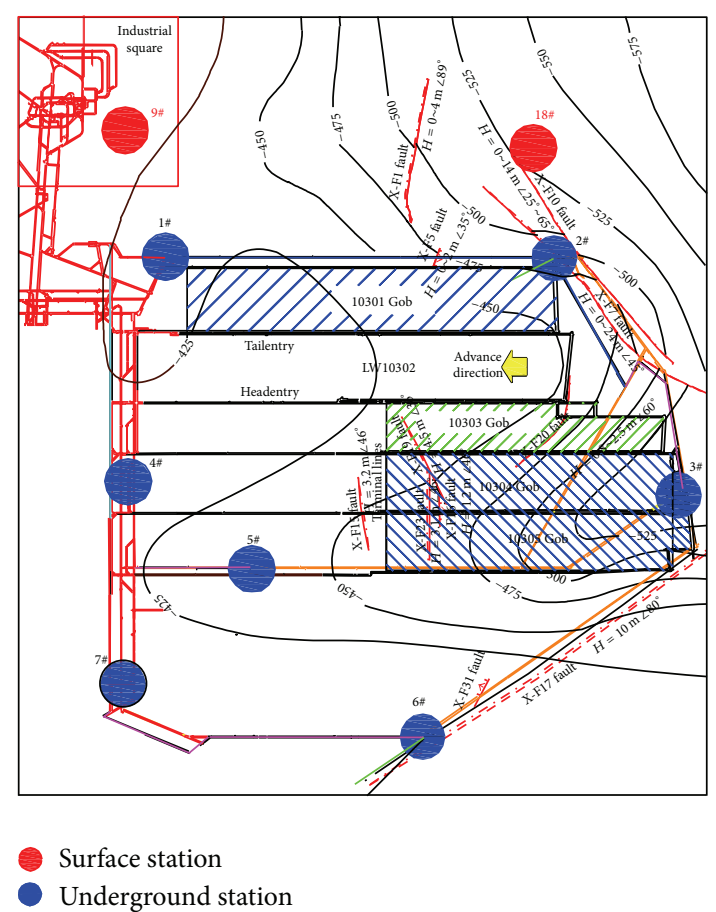

FIGURE 8: Layout of the seismic station around number 10 district in Baodiao coal mine.

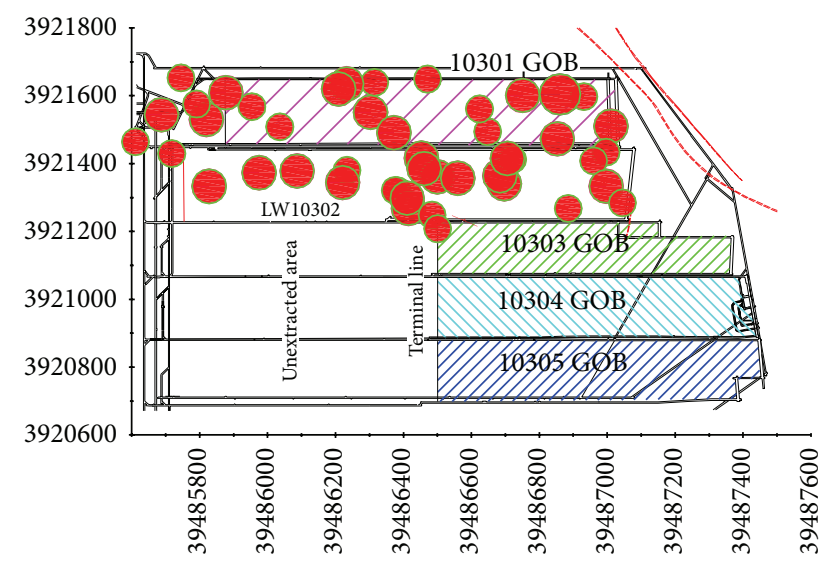

FIGURE 9: Tremors with energy exceeding $10^{5} \mathrm{~J}$ in the main key strata during the extraction of LW10302.

strata" that demonstrate the mechanism of big tremors is the rupture and caving of main key strata as the mining gobs increase leading to the suspension area exceeding the strength limit. Meanwhile the time-space series analysis suggests the breakage and movement of the main key strata that mining earthquakes at first occur in front of the LW10302 and then behind gobs of LW10301 and LW10302, cycling in the order with about $50-130 \mathrm{~m}$ step. This regulation further verified the famous "O-X" theory of key main strata that fracture ahead the work face and instable caving in the rear and of course some inevitable errors between field 


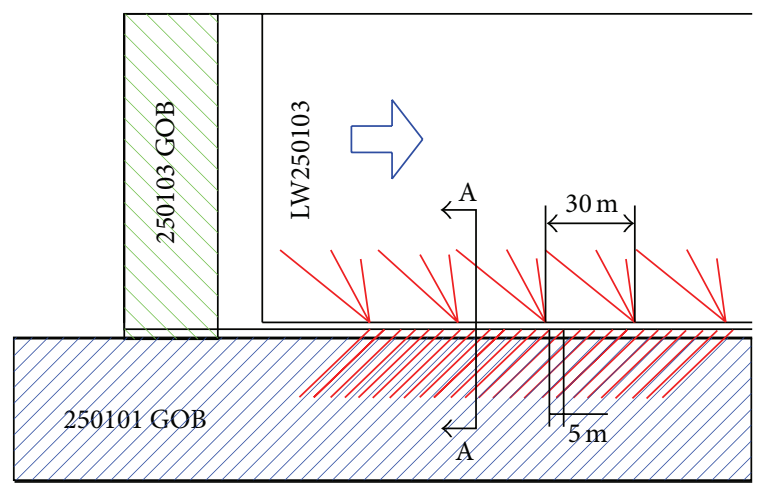

(a) Plan sketch of the deep hole blasting in the roof

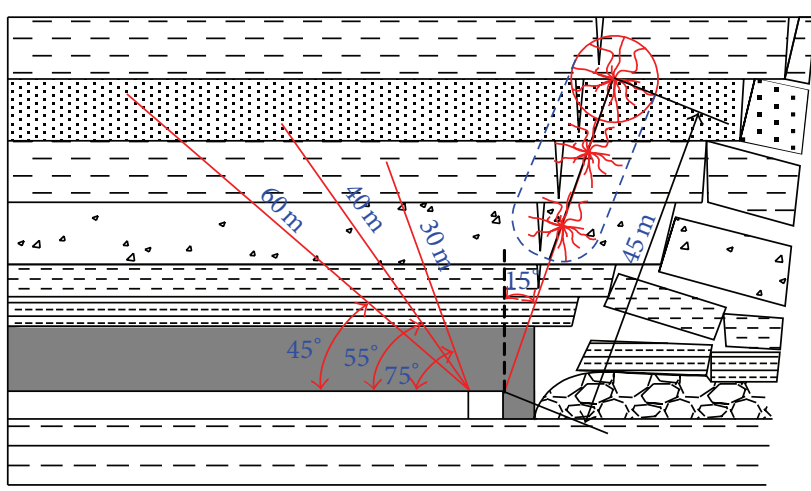

(b) A-A profile of deep hole blasting

FIGURE 10: Layout of the deep hole blasting during LW250103 mining.

monitoring results and theoretical calculation because of rock mass heterogeneity.

\section{Prevention to the Tremors in the Gob}

About $1-10 \%$ of the energy released by the tremor induced by key strata instability in gobs propagates in the form of seismic wave and imposes dynamic load on the coal and surrounding rock. The rock bursts will happen when the total energy that seismic energy $U_{S}$ superimposes with the elastic strain energy $U_{E}$ accumulated in coal and rock system exceeds the sum of the destruction dissipation and minimum impact energy based on the energy mechanism of rock burst, expressed by formula $U_{E}+U_{S} \geq U_{P}+U_{K}$. So the prevention for the dynamic damage to roadways by the tremors in gob should stop meeting the conditions. We put forward three methods to eliminate this disaster as follows: (1) initiative cutting low subkey strata: the directional hydraulic fracturing and deep hole blasting into the roof are two effective approaches [21]; (2) active impact resistant: the core content is to use closed supporting system with high strength and yield that can resist and absorb the seismic energy; the O-shell combined with bolt-wire-cable as well as door-hydraulic support can be adopted; and (3) active avoidance: this method is specially designed for thick coal seam; by changing the layout of the roadway, it transforms the gob-side entry to gob-below entry. Excavating the entry under the gob can avoid the influence of the key strata instability because the loose and broken rock mass can significantly dissipate the seismic wave, and at the same time, the entry under the gob is in the stress decreasing zone that makes the maintenance much more easily. Among these three methods, active avoidance is the most effective and economical, so a priority has to be suggested once the geology and technical conditions allowed. If the entry has already excavated, first the initiative cutting the subkey strata should be adopted to eliminate the seismic source and then strengthen the support of the entry. In Huating coal mine, we mainly used deep hole blasting method to cut down the subkey strata in the gob and work face to control mining tremors. Figure 10 shows the distribution and parameters of deep-hole blasting. The hole is $30-60 \mathrm{~m}$ deep with $40 \mathrm{~kg}$ mining explosive, and at the gob side the interval is $5 \mathrm{~m}$ in order to cut off the subkey strata, and at the other side it is $30 \mathrm{~m}$ that is approximately equal to the periodic weighting of LW250103 to reduce the weighting strength of the key strata.

Also during the coal wining of LW10302 in Baodian colliery, systematic deep-hole blasting into the roof is carried out thereby reducing the disaster effectively and guaranteeing the safety of miners.

\section{Conclusions}

To reveal the mechanisms of mining tremors induced by key strata movement and instability under large scale exploitation, we use elasticity theory and structural analysis to explain the instable process comprehensively; meanwhile the seismological observation system installed in Baodian coal mine supplied in site investigation results for authentication, and the following conclusions can be drawn.

(1) Small pillar cannot separate the connection and influence of the gobs adjacent to each other, and the balanced structure formed by the key strata is going to be instable again under the mining disturbance and then induces mining tremors that cause damage to roadways.

(2) Mechanisms of the mining tremors can be inducted into three basic types that are rotary and sliding instability of low subkey strata, shear sliding of the high subkey strata, and the main key strata rupture and cave at limit span.

(3) The time-space distribution of the seismic sources recorded by the SOS system indicates that the mining tremors show an evolution rule that first small tremors occurred in low subkey strata and then developed to high sub key strata with energy increasing greatly. And instability process of high subkey strata in the gob lags behind that in work face area.

(4) Tremors occur in the low subkey strata most frequently with lowest energy and those in the high sub key strata less than in the low subkey strata but with higher energy, tremors caused by main key strata 
have the least number but with the strongest energy; however, most damage to the work face and roadways is attributed to the shear and sliding instability of high subkey strata, and main key strata tremors impact the least due to being far away from the work face.

\section{Conflict of Interests}

The authors declare that there is no conflict of interests regarding the publication of this paper.

\section{Acknowledgments}

This work received financial support, provided by the Fundamental Research Funds for the Central Universities (2013QNB30); The National Basic Research Program of China (2010CB226805); The Twelfth Five-Year National Key Technology R\&D Program (2012BAK09B01); The Priority Academic Program Development of Jiangsu Higher Education Institutions (PAPD); and The Independent Foundation of State Key Laboratory of Coal Resources and Safe Mining (SKLCRSM10X05), which are gratefully acknowledged.

\section{References}

[1] J. Wu, X. R. Meng, and Y. D. Jiang, "Development of longwall top-coal caving technology in China," in Proceedings of the International Workshop on Underground Thick-Seam Mining, vol. 6, pp. 101-112, 1999.

[2] N. Zhang, L. Yuan, C. L. Han, J. H. Xue, and J. G. Kan, "Stability and deformation of surrounding rock in pillarless gob-side entry retaining," Safety Science, vol. 50, no. 4, pp. 593-599, 2012.

[3] H. P. Xie, Z. H. Chen, and J. C. Wang, "Three-dimensional numerical analysis of deformation and failure during top coal caving," International Journal of Rock Mechanics and Mining Sciences, vol. 36, no. 5, pp. 651-658, 1999.

[4] G. X. Xie, J. C. Chang, and K. Yang, "Investigations into stress shell characteristics of surrounding rock in fully mechanized top-coal caving face," International Journal of Rock Mechanics and Mining Sciences, vol. 46, no. 1, pp. 172-181, 2009.

[5] H. He, L.-M. Dou, S.-Y. Gong, P. Zhou, and Z.-J. Xue, "Rock burst rules induced by cracking of overlying key stratum," Chinese Journal of Geotechnical Engineering, vol. 32, no. 8, pp. 1260-1265, 2010 (Chinese).

[6] B. Unver and N. E. Yasitli, "Modelling of strata movement with a special reference to caving mechanism in thick seam coal mining," International Journal of Coal Geology, vol. 66, no. 4, pp. 227-252, 2006.

[7] X. Li, Z. Zhou, T.-S. Lok, L. Hong, and T. Yin, "Innovative testing technique of rock subjected to coupled static and dynamic loads," International Journal of Rock Mechanics and Mining Sciences, vol. 45, no. 5, pp. 739-748, 2008.

[8] J. Q. Jiang and K. Z. Zhang, "Cause and control method of mine earthquake in fully mechanized top coal caving mining," Chinese Journal of Rock Mechanics and Engineering, vol. 25, no. 1, pp. 3276-3282, 2006 (Chinese).

[9] A. McGarr, "Energy budgets of mining-induced earthquakes and their interactions with nearby stopes," International Journal of Rock Mechanics and Mining Sciences, vol. 37, no. 1-2, pp. 437443, 2000.
[10] A. T. Iannacchione, P. R. Coyle, L. J. Prosser, T. E. Marshall, and J. Litsenberger, "The relationship of roof movement and stratainduced microseismic emissions to roof falls," in Proceedings of the SME Annual Meeting, pp. 4-58, Denver, Colo, USA, 2004.

[11] H. Alehossein and B. A. Poulsen, "Stress analysis of longwall top coal caving," International Journal of Rock Mechanics and Mining Sciences, vol. 47, no. 1, pp. 30-41, 2010.

[12] P. K. Mandal, R. Singh, J. Maiti, A. K. Singh, R. Kumar, and A. Sinha, "Underpinning-based simultaneous extraction of contiguous sections of a thick coal seam under weak and laminated parting," International Journal of Rock Mechanics and Mining Sciences, vol. 45, no. 1, pp. 11-28, 2008.

[13] Z. L. Yang, "Stability of nearly horizontal roof strata in shallow seam longwall mining," International Journal of Rock Mechanics and Mining Sciences, vol. 47, no. 4, pp. 672-677, 2010.

[14] G. S. P. Singh and U. K. Singh, "Prediction of caving behavior of strata and optimum rating of hydraulic powered support for longwall workings," International Journal of Rock Mechanics and Mining Sciences, vol. 47, no. 1, pp. 1-16, 2010.

[15] M. G. Qian, X. X. Miao, J. L. Xu, and X. B. Mao, Key Strata Theory in Ground Control, China University of Mining and Technology Press, Xuzhou, China, 2000 (Chinese).

[16] M. G. Qian and P. W. Shi, Underground Pressure and Strata Control, China University of Mining and Technology Press, Xuzhou, China, 2003, (Chinese).

[17] F. Jiang, X. Zhang, S. Yang, L. Xun, Q. Ma, and H. Wang, "Discussion on overlying strata spatial structures of longwall in coal mine," Chinese Journal of Rock Mechanics and Engineering, vol. 25, no. 3, pp. 979-984, 2006 (Chinese).

[18] L. M. Dou, C. P. Lu, Z. L. Mu, and M. S. Gao, "Prevention and forecasting of rock burst hazards in coal mines," Mining Science and Technology, vol. 19, no. 5, pp. 585-591, 2009.

[19] L. M. Dou, Cases of Rockburst and Recent New Developments, China Science and Technology, Beijing, China, 2011.

[20] H. He, "Research on the evolution mechanism of spatial structure of overlying strata and rockburst inducing in coal mine," Meitan Xuebao, vol. 37, no. 7, pp. 1245-1246, 2012.

[21] H. He, L. M. Dou, J. Fan, T. T. Du, and X. L. Sun, "Deephole directional fracturing of thick hard roof for rockburst prevention," Tunnelling and Underground Space Technology, vol. 32, pp. 34-43, 2012. 

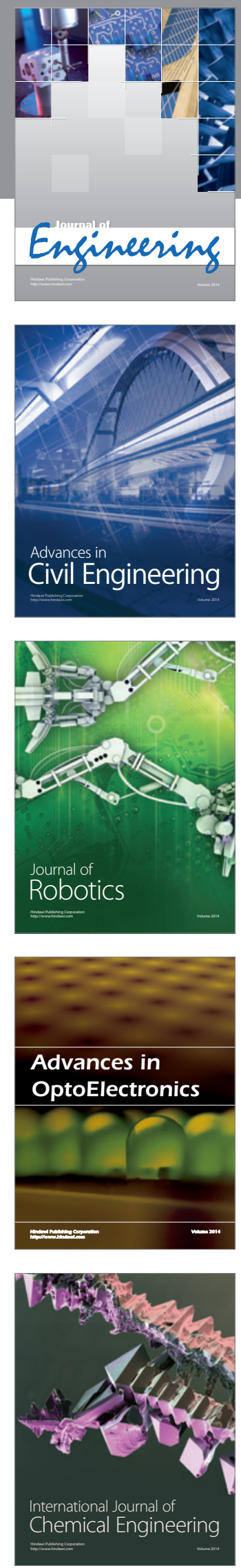

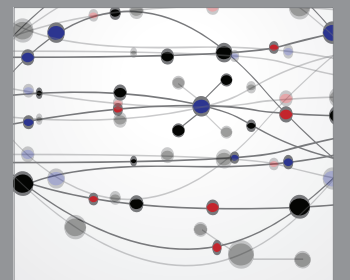

The Scientific World Journal
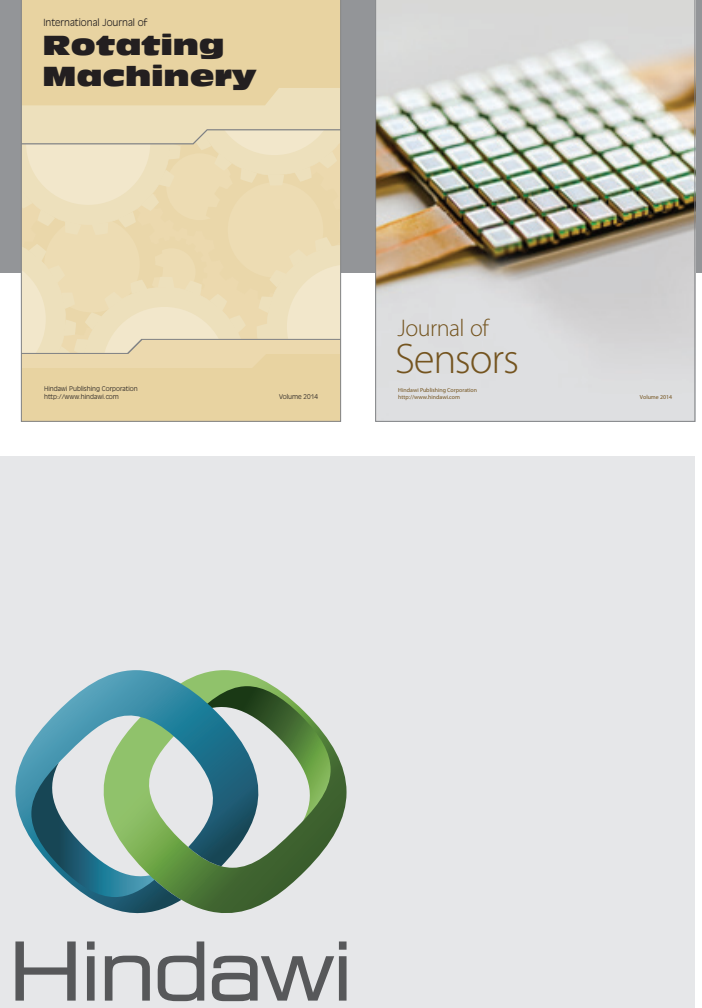

Submit your manuscripts at http://www.hindawi.com
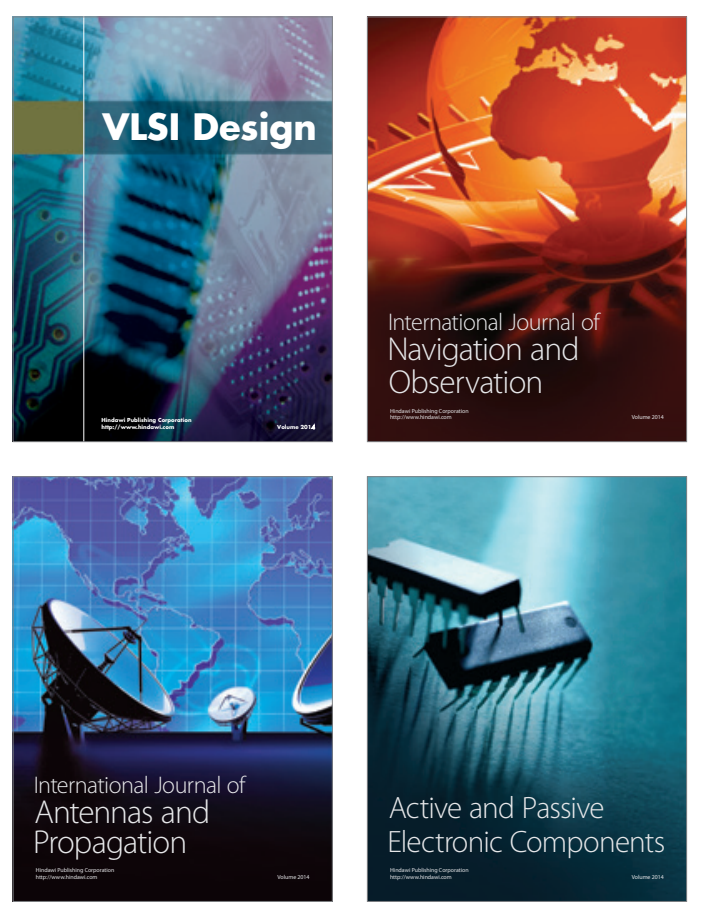
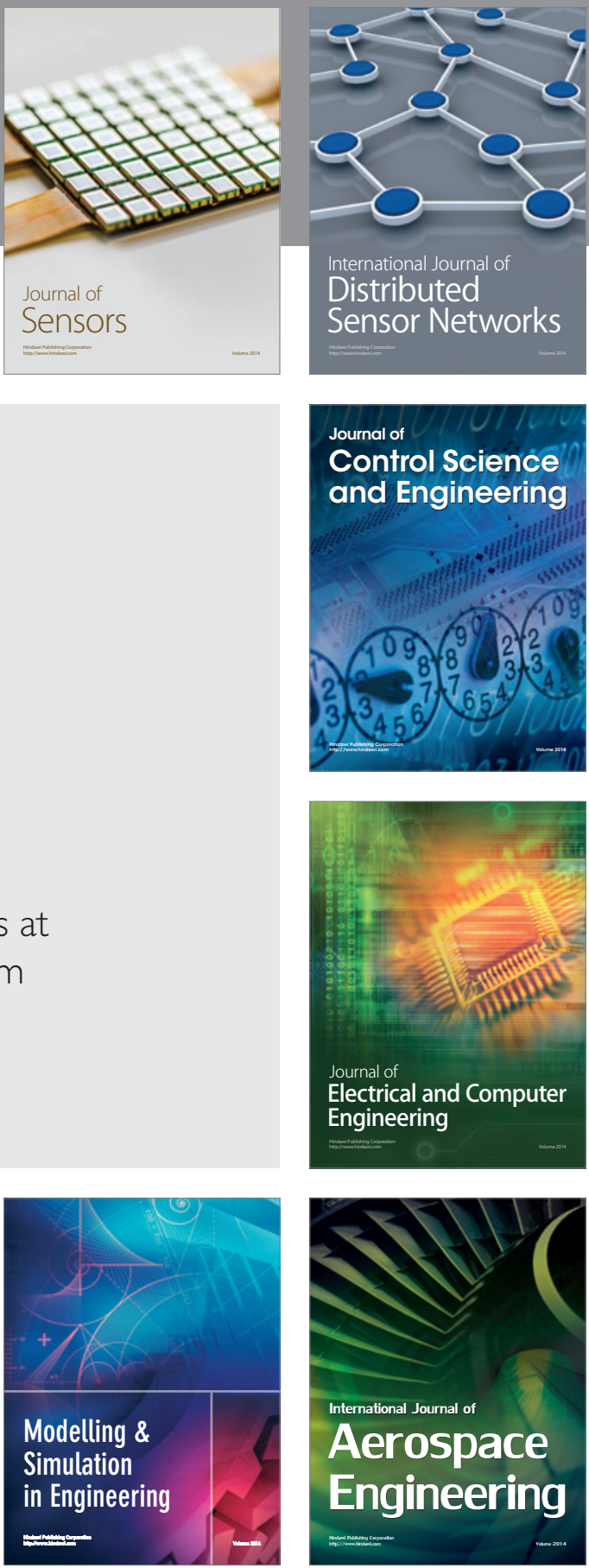

Journal of

Control Science

and Engineering
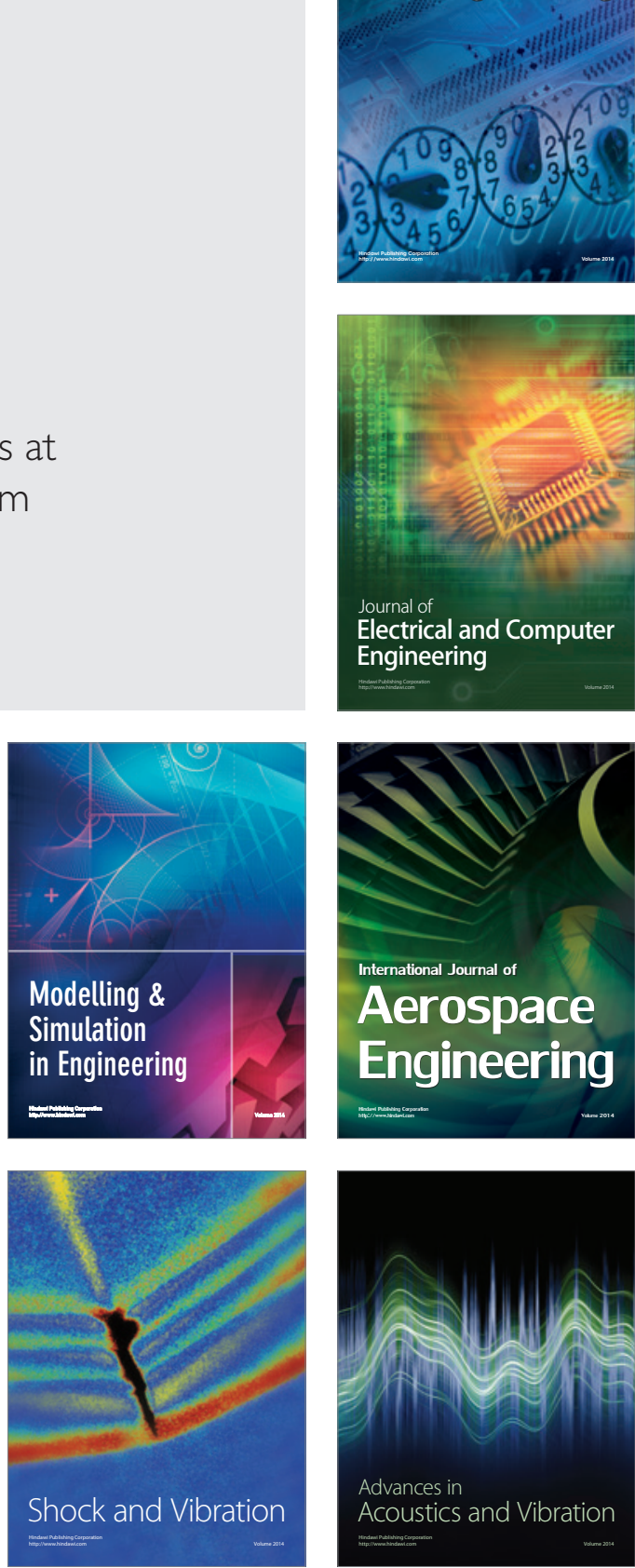